Supporting Information to

\title{
Permselective Ion Transport across the Nanoscopic Liquid/Liquid Interface Array
}

Xiao Huang, Lisiqi Xie, Xingyu Lin and Bin Su*

Institute of Analytical Systems, Department of Chemistry, Zhejiang University, Hangzhou 310058, China

Table of Content

S1. Preparation of SNM

S2. Electrochemical Characterization of the SNM/ITO

S3. Calculation of Trans-Membrane Resistance

S4. TEA ${ }^{+}$Transfer at the p-SiNF Supported Micro-ITIES Array

S5. DPVs for Charge Selectivity of the Nano-ITIES Array

S6. Charge Selectivity of the p-SiNF Supported Micro-ITIES Array

S7. Molecular Structures

S8. Size Selectivity of the p-SiNF Supported Micro-ITIES Array 


\section{S1. Preparation of SNM}

The SNM was grown on the ITO glass surface by the Stöber-solution growth approach. ${ }^{1}$ Firstly, the ITO glass was cleaned by $1 \mathrm{M} \mathrm{NaOH}$ ethanol solution, acetone, ethanol and water, sequentially. Then, it was immersed into the mixture containing water $(70 \mathrm{~mL})$, ethanol (30 mL), ammonia aqueous solution (10 $\mu \mathrm{L}, 25 \mathrm{wt} . \%)$, cetyltrimethylammonium bromide (CTAB, $0.16 \mathrm{~g}$ ), and tetraethoxysilane (TEOS, $80 \mu \mathrm{L})$ under quiescent condition at $60{ }^{\circ} \mathrm{C}$ to grow the SNM. After $24 \mathrm{~h}$, the SNM/ITO was rinsed with water quickly, then aged at $100{ }^{\circ} \mathrm{C}$ overnight. The $\mathrm{CTAB}$ micelles in the silica nanochannels were removed by immersing the $\mathrm{SNM} / \mathrm{ITO}$ in $0.1 \mathrm{M} \mathrm{HCl}$ ethanol solution for 15 min under stirring.

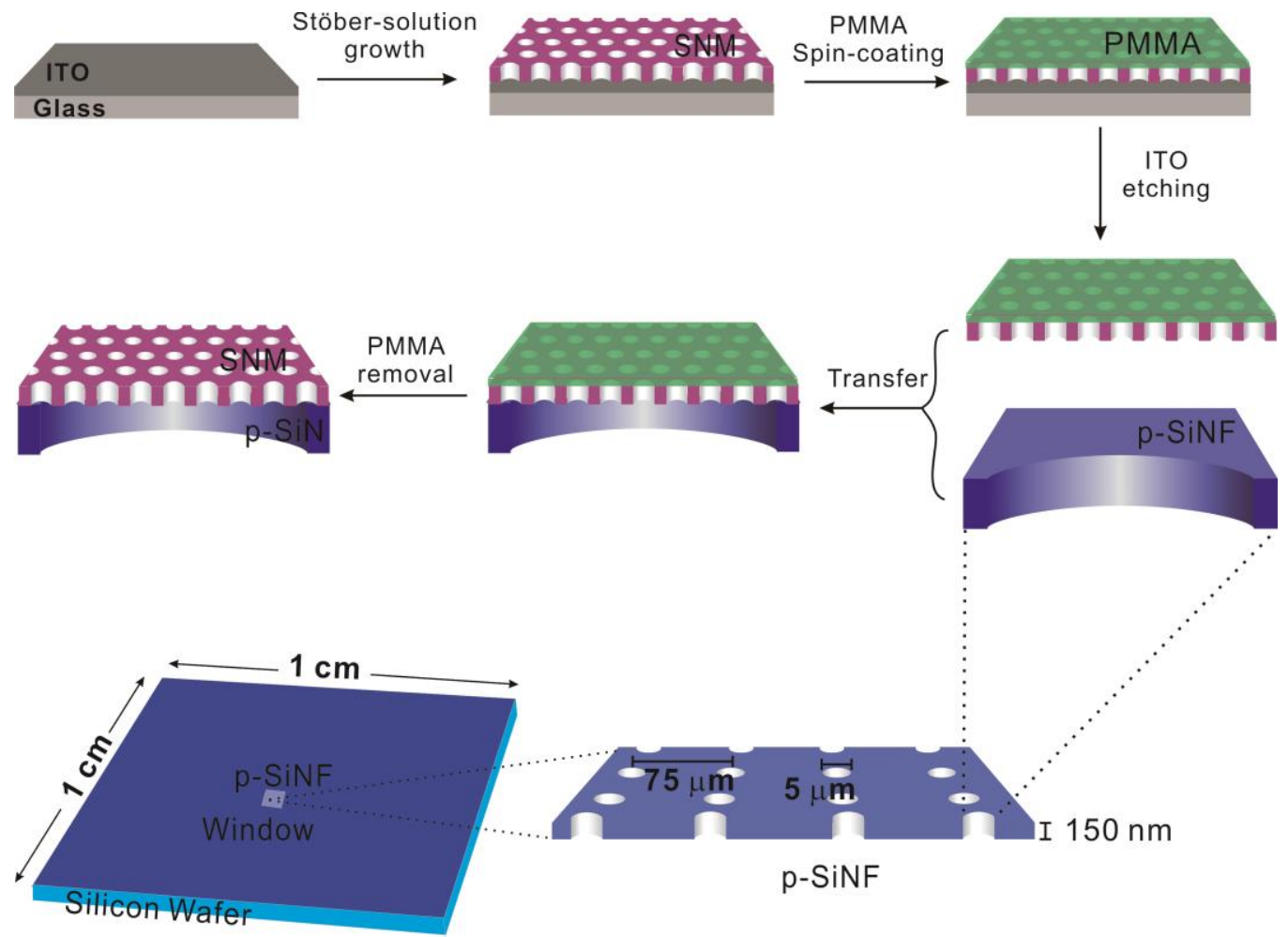

Figure S1. The procedure for the preparation of SNM/p-SiNF with a perforated window in the form of nanochannels-on-micropores. 
The free-standing SNM supported by p-SiNF chip was prepared as we reported in a previous work. ${ }^{2}$ As shown in Figure S1, a thin layer of poly(methyl methacrylate) (PMMA, $\left.M_{\mathrm{w}}=996000\right)$ was firstly spin-coated on the SNM/ITO at $2000 \mathrm{rpm}$ for $30 \mathrm{~s}$, the PMMA/SNM/ITO was baked at $115{ }^{\circ} \mathrm{C}$ for 15 min. Then, the PMMA/SNM/ITO was immersed in $\mathrm{HCl}$ solution (2 $\mathrm{M}$ ) overnight to etch the ITO layer, thus getting the freestanding PMMA/SNM (To be mentioned that direct etching ITO without PMMA protection will only yield SNM fragments). Subsequently, a SiN/Si chip was used to fish the PMMA/SNM out of the water. The chip was further dried at $100{ }^{\circ} \mathrm{C}$ for $2 \mathrm{~h}$ to enhance the chemical bonding between SNM and SiN, considering silanol groups are present on both surfaces. Finally, the top PMMA layer was dissolved in acetone. Thanks to the presence of silanol groups on both SNM and p-SiNF surfaces, they can strongly bond together and thus possess excellent chemical and thermal stability. 


\section{S2. Electrochemical Characterization of the SNM/ITO}

The SNM grown on the ITO surface was firstly characterized by conventional threeelectrode CV measurements in potassium hydrogen phthalate (KHP) buffer solutions $(\mathrm{pH}$ $=4.0)$ containing two oppositely charged redox probes, namely $\mathrm{Ru}\left(\mathrm{NH}_{3}\right)_{6}{ }^{3+}$ and $\mathrm{Fe}(\mathrm{CN})_{6}^{3-}$. The SNM/ITO functioned as the working electrode, with a platinum wire and a silver/silver chloride electrode as the counter and reference electrodes, respectively.

Figure S2 compares CVs of a bare ITO electrode (black curves), CTAB/SNM/ITO electrode (blue curves) and SNM/ITO electrode (red curves). No Faradaic current was observed for both $\mathrm{Ru}\left(\mathrm{NH}_{3}\right)_{6}{ }^{3+}$ and $\mathrm{Fe}(\mathrm{CN})_{6}{ }^{3-}$ at the $\mathrm{CTAB} / \mathrm{SNM} / \mathrm{ITO}$, indicating that the ITO surface is fully covered by the SNM without cracking or leakage and that CTAB micelles fill all nanochannels in the SNM to block the mass transport of redox probes. In contrast, after removal of CTAB micelles, redox current was observed for both probes. Additionally, the current magnitude of $\mathrm{Ru}\left(\mathrm{NH}_{3}\right)_{6}{ }^{3+}$ is apparently larger than that of $\mathrm{Fe}(\mathrm{CN})_{6}{ }^{3-}$. This permselective behavior can be ascribed to the ultrasmall size of silica nanochannels (2-3 nm in diameter) and their negatively charged surface. As illustrated in Figure S2c, the surface of silica nanochannels is negatively charged due to the deprotonation of silanol groups with an isoelectric point of $2 \sim 3 .^{3}$ Therefore, apart from the diffusion, the electric field in the radial direction of nanochannels, or the electrical double layer, will also contribute to the mass transport. As a result, the mass transport of $\mathrm{Ru}\left(\mathrm{NH}_{3}\right)_{6}{ }^{3+}$ with the opposite sign is favored, whereas that of $\mathrm{Fe}(\mathrm{CN})_{6}{ }^{3-}$ with the same sign is suppressed. 

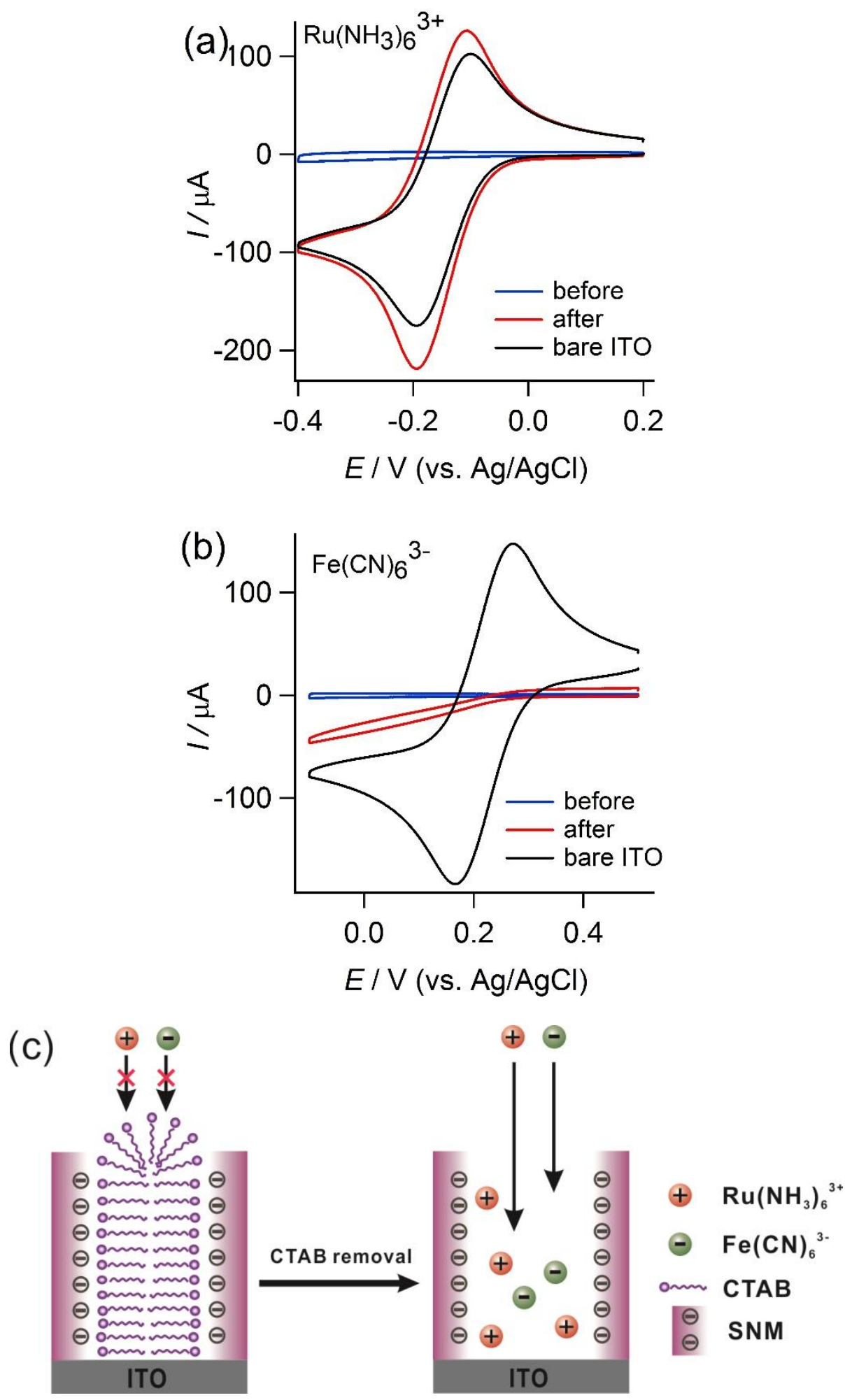

Figure S2. (a, b) Cyclic voltammetry (CV) of the SNM/ITO in $50 \mathrm{mM} \mathrm{KHP}(\mathrm{pH}=4.0)$ containing two redox probes before and after surfactant removal: (a) $0.5 \mathrm{mM} \mathrm{Ru}\left(\mathrm{NH}_{3}\right)_{6}{ }^{3+}$; (b) $0.5 \mathrm{mM} \mathrm{Fe}(\mathrm{CN})_{6}{ }^{3-}$. (c) Illustration of mass transport of two oppositely charged probes at the CTAB/SNM/ITO and SNM/ITO electrodes. 


\section{S3. Calculation of Trans-Membrane Resistance}

The nanochannels array acts like a high density of resistors in parallel. As a first approximation, the array resistance can be calculated by, ${ }^{4}$

$$
\mathrm{R}_{\mathrm{n}}=\rho \frac{L}{N_{\mathrm{n}} \pi r_{\mathrm{n}}^{2}}
$$

where $\rho$ is the resistivity of the solution filling the nanochannel, in the present case the aqueous phase. $N_{\mathrm{n}}$ is the number of nanochannels confined by each $\mathrm{SiN}$ micropore and equal to $4.0 \times 10^{4} \times \pi r_{\mathrm{a}}^{2}=7.9 \times 10^{5}\left(r_{\mathrm{a}}=2.5 \mu \mathrm{m}\right) . L$ and $r_{\mathrm{n}}$ are the nanochannel length and radius, respectively. Considering a resistivity of $9.30 \Omega \mathrm{m}$ for an aqueous solution containing $10 \mathrm{mM} \mathrm{LiCl},{ }^{5}$ the resistance of one nanochannel array is $2.0 \times 10^{5} \Omega$ according to eq. S-1. It can be seen that the array resistance is very small due to a high channel density, even though the resistance in a single nanochannel is significantly larger, $1.6 \times 10^{11} \Omega$.

Similarly, the resistance of one SiN micropore filled with organic electrolyte was estimated to be $1.6 \times 10^{5} \Omega$, using a resistivity of $20.96 \Omega \mathrm{m},{ }^{6}$ pore depth of $150 \mathrm{~nm}$ and a pore radius of $2.5 \mu \mathrm{m}$. Therefore, the trans-membrane resistance for one set of nanochannel array on a micropore is dominated by the micropore resistance filled with organic electrolyte.

The total trans-membrane resistance for the nano-ITIES array supported by $4 \times 4$ micropores was roughly $2.2 \times 10^{4} \Omega$. 
S4. TEA $^{+}$Transfer at the Bare p-SiNF Supported Micro-ITIES Array

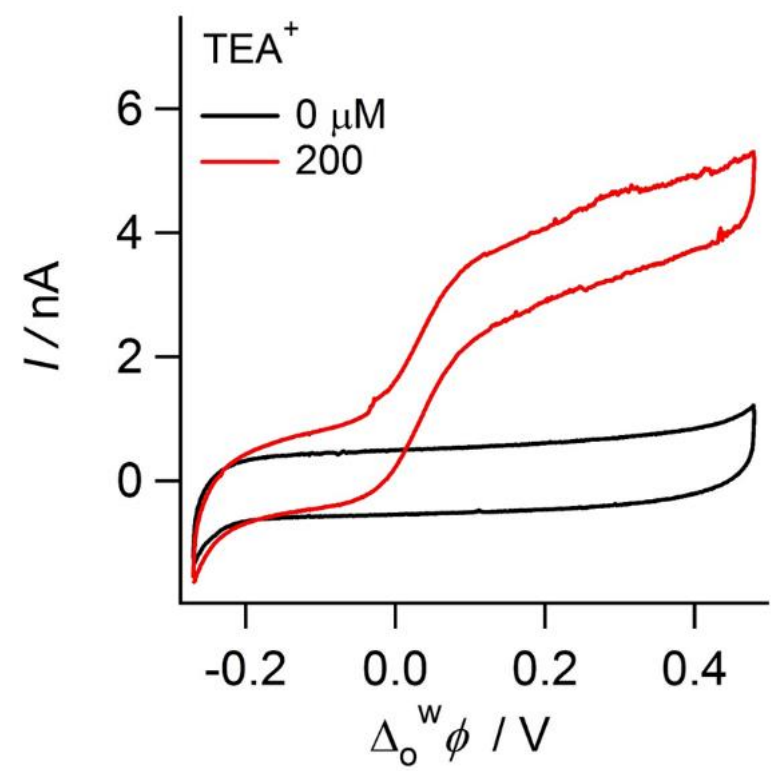

Figure S3. Cyclic voltammograms (CVs) obtained at the bare p-SiNF supported microITIES array using the cell 1 illustrated in Scheme $1 \mathbf{b}$ at a scan rate $20 \mathrm{mV} \mathrm{s}^{-1}$ in the absence or presence of $\mathrm{TEA}^{+}: x=0$ (black curve), $x=200$ (red curve). 

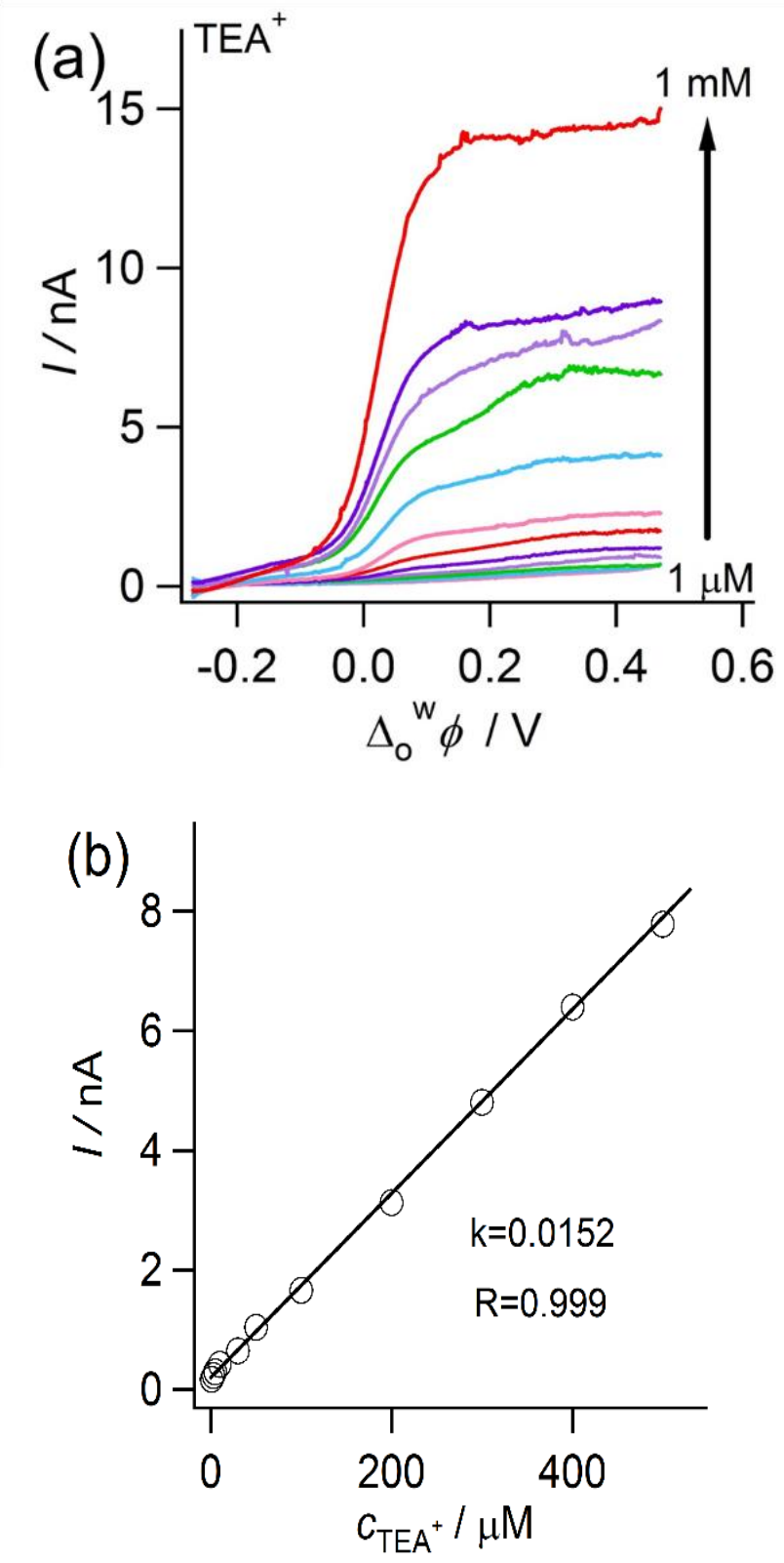

Figure S4. (a) Background-subtracted voltammograms (forward scan only) obtained at the bare p-SiNF supported micro-ITIES array using the cell 1 illustrated in Scheme $\mathbf{1 b}$ at a scan rate $20 \mathrm{mV} \mathrm{s}^{-1}$ and various concentrations of $\mathrm{TEA}^{+}: x=1,3,5,10,30,50,100,200$, 300, 400, 500, 1000 (up-to-down). (b) The calibration curve plots of the background subtracted limiting currents (forward scans, around the potential of $0.1 \mathrm{~V}$ ) against TEA ${ }^{+}$ concentrations $(0-500 \mu \mathrm{M})$. The solid line is the linear fitting of the experimental data. 


\section{S5. DPVs for Charge Selectivity of the Nano-ITIES Array}
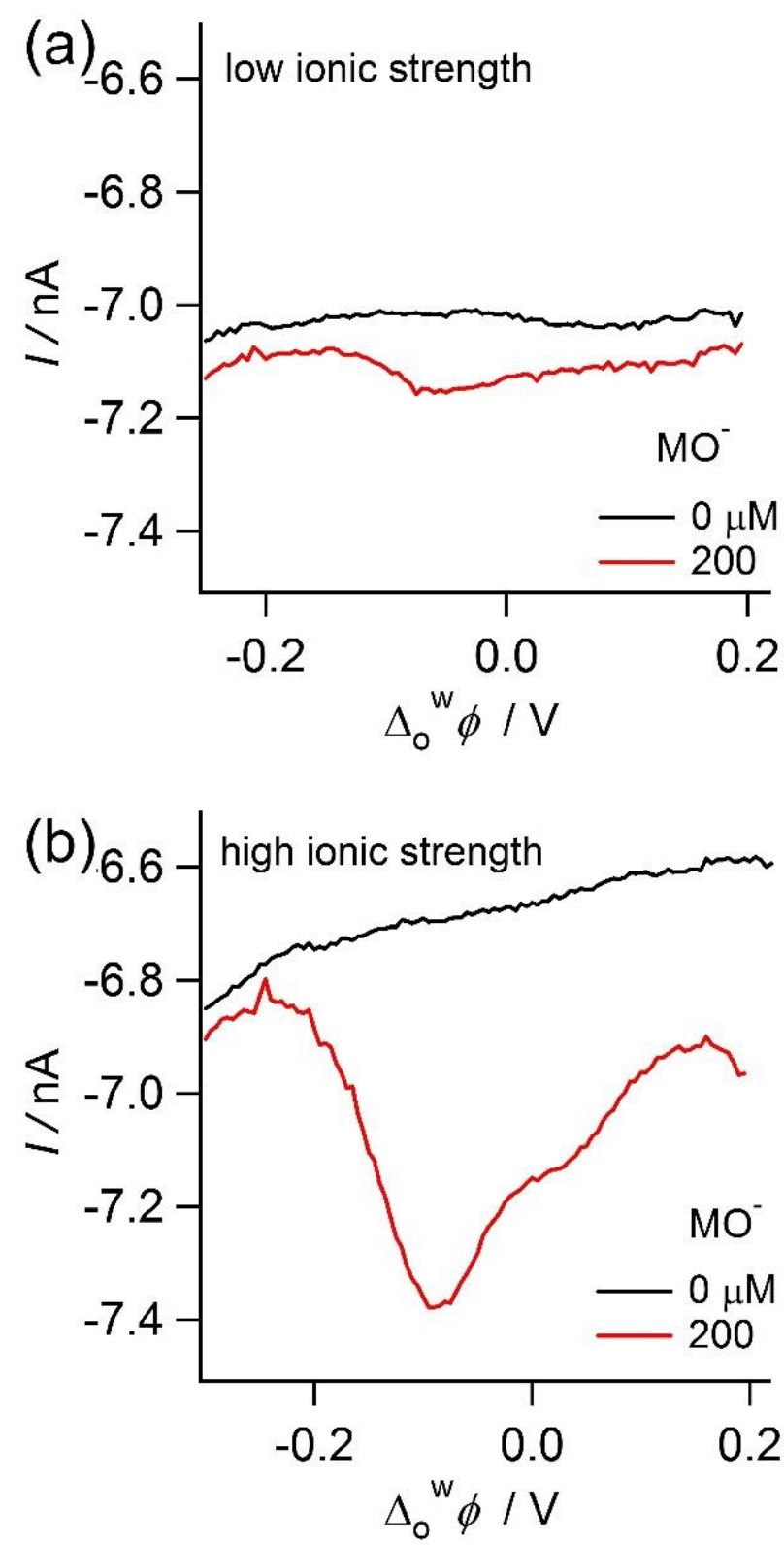

Figure S5. DPVs obtained at a water /DCE interface with the cell 2 illustrated in Scheme $1 \mathrm{~b}$ at a scan rate $20 \mathrm{mV} \mathrm{s}^{-1}$ in the absence or precence of $200 \mu \mathrm{M}$ methyl orange anion $\left(\mathrm{MO}^{-}\right)$in low $(\mathrm{a}, y=1)$ and high $(\mathrm{b}, y=100)$ ion strength transfer across SNM/p-SiN supported nano-ITIES. 
S6. Charge Selectivity of the p-SiNF Supported Micro-ITIES Array
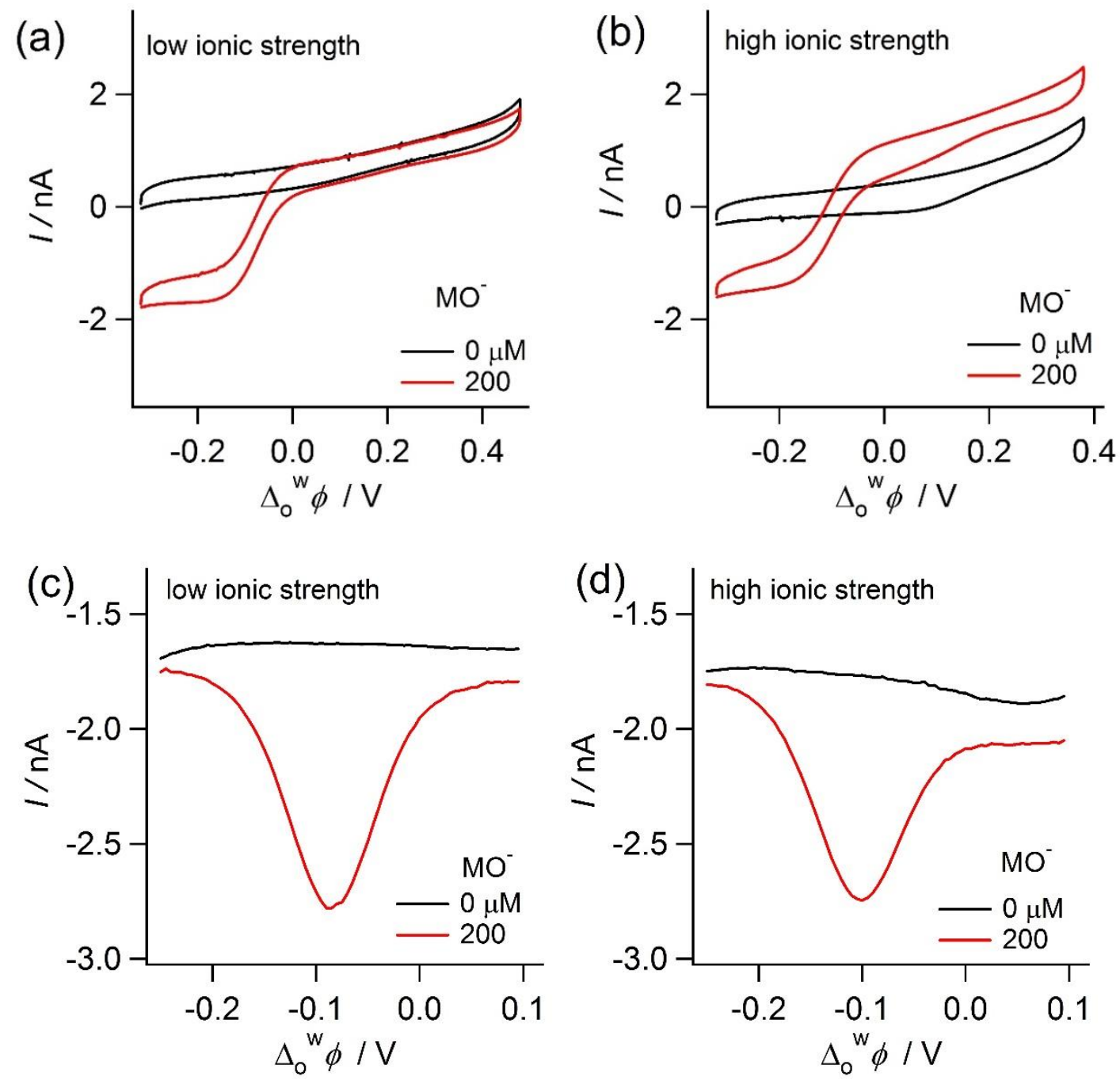

Figure S6. CVs (a, b) and DPVs (c, d) obtained at the p-SiNF supported micro-ITIES array using the cell 2 illustrated in Scheme $1 \mathbf{b}$ at a scan rate $20 \mathrm{mV} \mathrm{s}^{-1}$ in the absence or presence of $200 \mu \mathrm{M} \mathrm{MO}^{-}$at a low (a and c, $\left.y=1\right)$ and high (b and d, $y=100$ ) ion strength. 
S7. Molecular Structures

(a)<smiles>CC[N+](CC)(CC)CC</smiles>

TEA $^{+}$ (b)<smiles>Cc1ccc([Se][Na])cc1</smiles>

$\operatorname{Tos}^{-}$ (c)<smiles>CN(C)c1ccc(N=Nc2ccc(S(N)(=O)=O)cc2)cc1</smiles>

MO (d)

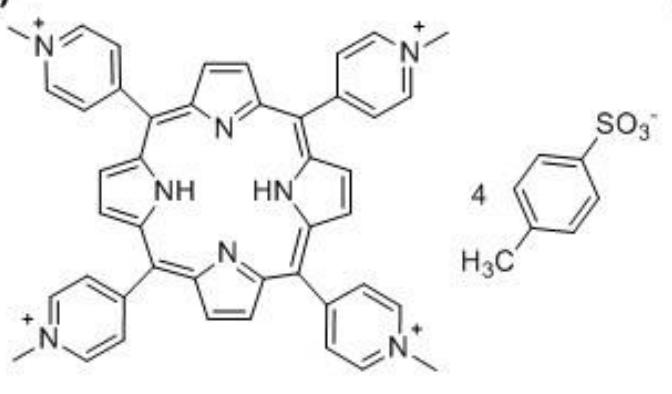

$\mathrm{H}_{2} \mathrm{TMPyP}^{4+} \div 4 \mathrm{TOS}^{-}$ (e)

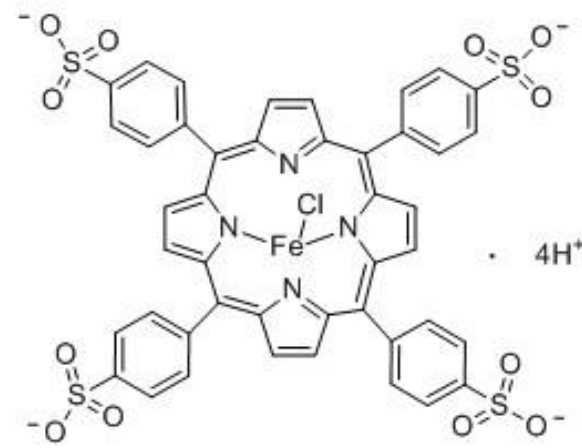

FeTPPS $^{4-} \cdot 4 \mathrm{H}^{+}$

Figure S7. Molecular structures of analytes used in this study. 
S8. Size Selectivity of the p-SiNF Supported Micro-ITIES Array
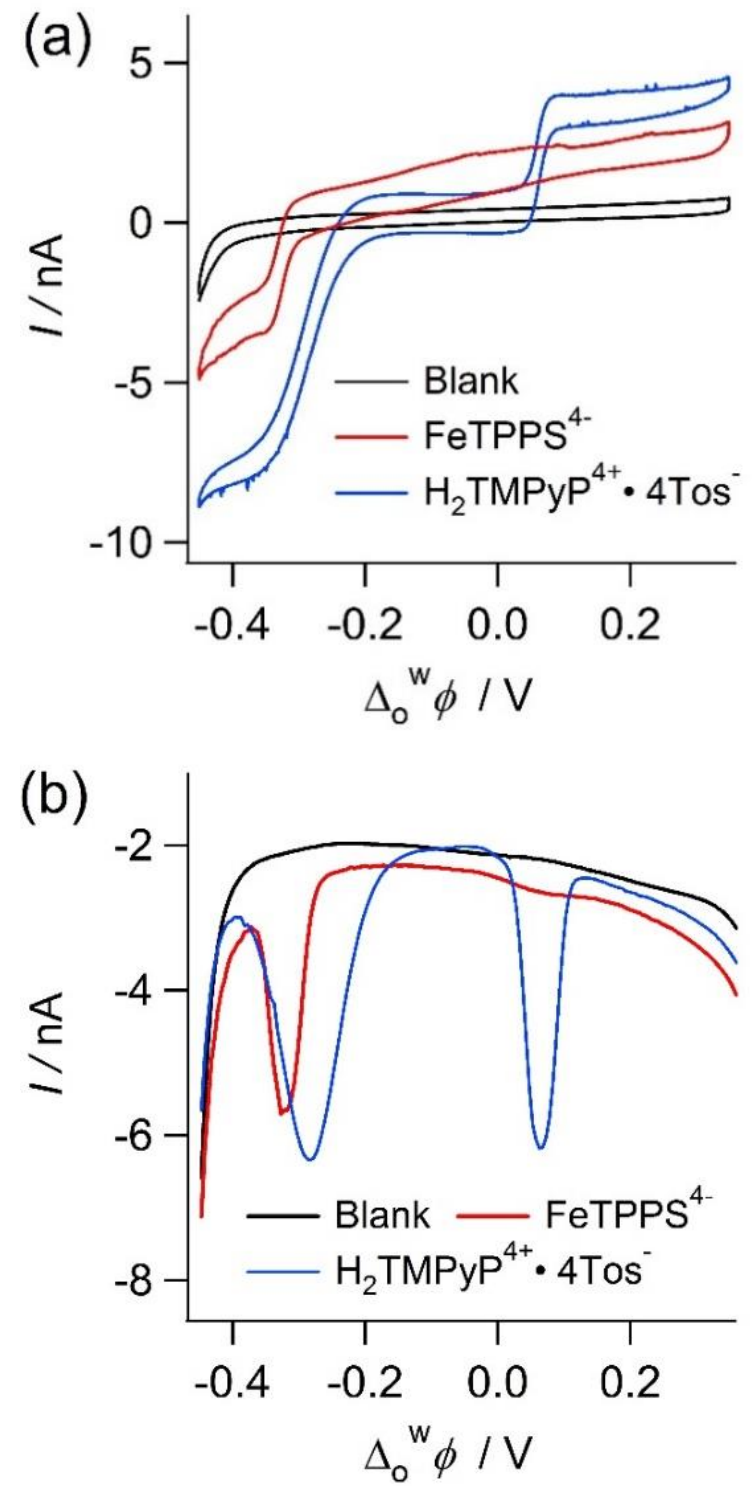

Figure S8. CVs (a) and DPVs (b) obtained at the micro-ITIES array using cell 2 illustrated in Scheme $1 \mathbf{b}$ at a scan rate $20 \mathrm{mV} \mathrm{s}^{-1}$ in the absence (black curves) and presence of 200 $\mu \mathrm{M} \mathrm{FeTPPS}{ }^{4-}$.(red curves) or $\mathrm{H}_{2} \mathrm{TMPyP}^{4+}$.4Tos ${ }^{-}$(blue curves). The aqueous electrolyte was $100 \mathrm{mM} \mathrm{Li}_{2} \mathrm{SO}_{4}$. 


\section{References}

(1) Teng, Z.; Zheng, G.; Dou, Y.; Li, W.; Mou, C.-Y.; Zhang, X.; Asiri, A. M.; Zhao, D. Angew. Chem. Int. Ed. 2012, 51, 2173.

(2) Lin, X.; Yang, Q.; Ding, L.; Su, B. ACS Nano 2015, 9, 11266.

(3) Etienne, M.; Quach, A.; Grosso, D.; Nicole, L.; Sanchez, C.; Walcarius, A. Chem. Mater. 2007, $19,844$.

(4) Deblois, R. W.; Bean, C. P.; Wesley, R. K. A. J. Colloid. Interf. Sci. 1977, 61, 323.

(5) Patnaik, P.; Dean, J. A. Dean's analytical chemistry handbook; McGraw-Hill, 2004.

(6) Kontturi, A. K.; Kontturi, K.; Manzanares, J. A.; Mafe, S.; Murtomaki, L. Ber. Bunsen-Ges. Phys. Chem. 1995, 99, 1131. 